\title{
On problem-driven integrated design and practice of ability promotion for young teachers in civil aviation unique specialty
}

\author{
Jingjie Chen \\ College of Aviation Automation \\ Civil Aviation University of China \\ Tianjin, China \\ jjchen@cauc.edu.cn
}

\author{
Yujuan Zhu \\ College of Aviation Automation \\ Civil Aviation University of China \\ Tianjin, China \\ 1923244090@qq.com
}

\begin{abstract}
This paper aims to promote the ability of young teachers for industry-college like Civil Aviation University of China (CAUC). On the basis of a large number of investigation and study, according to the new requirements about young specialty teacher development in CAUC, that is used to carry out electrical teaching used for maintenance engineering, an integrated plan is put forward. The plan is considered the following two preconditions. One is the gaps found. The other is to emphasize the integrated effects of top-level design and development effectiveness of teachers' ability. The plan is a closed loop control logic solution. It is made up of theoretical teaching, experimental teaching, engineering practice and limited objective evaluation and improvement. The implementation of the program shows the universal significance to continuously improve the ability of teachers by means of problem-driving and task-pulling.
\end{abstract}

Keywords-colleges and universities; problem driven; engineering education; young teachers; ability promotion formattin

\section{INTRODUCTION}

Today it has become a consensus to constantly improve the teaching quality of education by deepening reform of the education teaching and insisting on connotative development read. The key to obtain the expected results lies in the teachers, especially the young and middle-aged teachers and their teaching ability of continuous promotion [1]. It is because of the fact that the young teachers have indeed become the main force of teaching body in any colleges and universities (C\&U). Statistics show that young teachers under the age of 40 take up over $60 \%$ of the total number of full-time teachers in C\&U. According to statistics which is carried out by the Ministry of Education of the people's republic of China, the teachers under the age of 45 (excluding) have accounted for a little more than $72 \%$. The situation in Civil Aviation University of China (CAUC) is similar, too. For example, in college of aviation automation of CAUC, at the end of June 2015, the professional teachers under the age of 30 years old accounted for $10.87 \%$. And the 30 to 40 years old teacher, the 40 to 50 years old ones, and over 50 years old ones respectively were $55.43 \%, 10.57 \%$ and $14.13 \%$. Such is Tianjin. Furthermore, if we investigate the teaching tasks in the last years, we can find that middle-aged and young teachers in college of aviation automation of CAUC are absolute main bodies of teaching.

\section{HighER EDUCATION OF OUR COUNTRY'S HiGH STANDARDS OF THE CONTINUOUS IMPROVEMENT OF YOUNG TEACHER'S COMPREHENSIVE ABILITY}

On the macro, the teachers should first understand the national standards of higher education in China and abroad. From a macro point of view [2-5], University teachers should be able to obtain sustainable professional development [6], Put enough time, energy and emotion [7], More need to have a certain academic ethics and academic value [8], and then meet the teaching ability structure model expression [9], must have the concrete method, must reflect the teacher ability training the design [10-11].

Medium In view, the colleges and universities should make a system guarantee for the development of young teachers [12]. Including, around the introduction of top-notch youth and training, to upgrade the level of internationalization as the goal, to the starting point of the mechanism of Personnel System Reform Commission, increase support of young teachers, young teachers rapid growth and create a good atmosphere and environment, it is necessary to young teachers team construction idea, also want to have specific construction measures The former must be four combined/The former must be four binding: 1) The combination of the construction of young teachers' team and the development of discipline; 2) Incentive mechanism and competition mechanism; 3 ) Combination of personnel training and personnel training; 4) Employment mechanism and transfer mechanism. The latter should be done Solicit, excavate, research, reserve, stability/ Attract, mining, training, reserves, solid, Foundation is system construction. To continuously improve the system of young teachers training as a leader, attracting first-class elite youth, mining outstanding young talents, looking at the international training subjects, promote scale talent reserve, solid logistics of young teachers are very important. In turn, the young teachers in Colleges and universities must have a thorough grasp of the basic theory of school personnel training strategy and personnel training, e.g. "Recent development zone". For 
example, taking into account the mass of the elite education under the new normal, the implementation of the hierarchical classification of Higher Education is needed. A new requirement for teacher's comprehensive ability is put forward [13].

\section{PROBLEMS EXISTING IN THE DEVELOPMENT OF YOUNG TEACHERS IN INDUSTRY COLLEGE}

Heavy teaching task greatly limits the development and growth of young teachers. At present, the major teachers of CAUC are those winners of doctoral degree who are mainly derived from the University and Research Institute. But these postgraduate training institutions have almost no similar subject relative to CAUC, so they are bound to face a painful transformation process. Otherwise they will go away from the practice on civil aviation transportation what they should service. In a sense, the industry colleges are in the existence of such a problem or a similar problem. And these transformations will cost them plenty, such as a lot of inputs of time and financial resources, including that of organizational aspects and personal ones.

First, a deeper reason is the lack of top-level design or at least incomplete one in young teacher development process in Industry College. As the president Binglin Zhong of Beijing Normal University said all aspects must be try their best to provide necessary support condition. The government should construct national training system for young teachers, including teachers' qualifications and qualification certification, the national fund guarantee and the teaching evaluation and discipline evaluation standard, etc.. Second, it is not enough to know and understand the inner law of young teachers' growth. Academician zikun Wang of Chinese Academy of Science believes that young teachers play a role of connecting link between the preceding and the following. They are needed to assist their teachers to finish the heritage work and to give students imparting knowledge. So he advocates a plan to arrange their teaching work by their interest and expertise. And it is a process to grow slowly. There should be a sequence. It should be from simple to difficult process to grow slowly. The word "slow" contains a very rich meaning. That is why the development of teachers has its law. Third, the development of young teachers lack of specific, operational procedures or projects. Objectively, the young teachers in our university are provided with the basic conditions of qualified teachers, and the comprehensive ability to improve the space is there, the key is how to do. In 2015, Xuming Wang said education in particular needs to further reform and needs more ideological emancipation. He bluntly pointed that problem consciousness and pragmatic and effect actions are need. Especially like special electric teacher in civil aviation maintenance field should be more worthy of contemplation of the professional teachers, because it is very different from characteristics of the needs of professional teaching in general colleges ${ }^{[15]}$. Perhaps, some inspirations can be getting from the process of the construction of teachers' team of young professional maintenance engineering which Chinese Civil Aviation Flight University has finished.

Therefore, combined with part of the results of Tianjin college undergraduate teaching quality and teaching reform research plan project, a comprehensive scheme to enhance aviation specific professional young teacher's ability based on the mode of problems driven and benchmarking requirements and perfect solutions is put forward.

\section{TOP-LEVEL DESIGN IDEA OF IMPROVING YOUNG TEACHERS' COMPREHENSIVE ABILITY}

\section{A. Special Requirements For the Promotion of Young Teachers in Our University}

The electronic information engineering specialty in our university has its own special meanings compared with other C\&Us. Its training program has not only covered the same professional requirements of other institutions, but also includes the core teaching content requirements of automatic control specialty, radio communication specialty and instrument specialty [16-18]. Because it is not only to reflect the laws of professional higher education, but also to focus on the practical needs of industry engineering services, the requirements of the professional teachers directly reflected breadth requirement under the depth of the need to meet the requirements of professional higher education. It is a typical mixture of higher education and professional engineers. Therefore, it is necessary to develop the teachers' ability with a large engineering view.

\section{B. Customized Design of Comprehensive Solution on Improving Young Teacher Ability in Our University}

Since it is a comprehensive program, it is bound to have a choice. Therefore, to enhance the ability of young teachers, the overall program design ideas is to build project of the general idea and scheme combined with the professional personnel training trait, which is on the basis of a large amount of investigation. The principle what we insist is to do or not do on the certain things. And adhering to the high engineering education connotation must be adhered to, so does leak fill a vacancy and retain the large, release the small. That is, the toplevel design driven by the problem is constructed on the basis of refinement on the historical process. It is important to have targeted analysis and processing. So a right solution can be get.

According to the analysis of the demand of the problem, the integrated scheme of the fine task driving type is proposed. And based on the closed loop control logic of "theoretical teaching, experimental teaching, engineering practice and limited target evaluation and improvement", the experimental project which is to improve the professional teachers' ability is constructed.

In practice, the first step is to break the boundary of course. According to the integrity of knowledge system and coherent to avionics systems, four courses which include avionics maintenance base, modern avionics maintenance technology, maintenance management and airworthiness regulations are integrated, and then broken down into three training subjects named basic theory teaching and training, course experiment project training and Engineering practice project. They are relatively independent and mutually connected professional training courses. The professional team of trainee will be organized in this connection. 


\section{Result Analysis of Young Teacher Training Course}

\section{1) Subject one}

It is for the design of improving ability to theoretical teaching. The training objectives are to creatively form independent connotation of comprehensive teaching methodology. It can be served for teaching implementation in civil avionics maintenance course by the engineering handbook comparison of Airbus and Boeing aircraft models.

Training case: Taking the CFDS system of A320 and CMS system of B777 system as the object, the trainees of young teachers are required to compare and analyze the two kinds of intelligent diagnosis system of airborne electronic system.

Training results: After three months, the four trainees found that the two typical airborne electronic systems are used to complete the initial detection of the fault detection and the intelligent diagnostic process is the same. But the two systems of intelligent diagnosis system, including physical structure of the composition, diagnostic mechanism, interface protocol, data storage method and realization of diagnostic function, are different. This is a qualitative leap in the rich content of young teachers.

\section{2) Subject two}

It is for design and development of experiment teaching project in course. The training objectives are for professional teachers to complete autonomy and accept the test of students' experimental results. And they themselves experience the fun of learning in doing and improving in teaching and the synchronization of doing with learning and teaching.

Training case: The design and development of experiment project in the course of modern aviation electronic maintenance technology

Training results: Developments of two experimental projects have been finished. One is auxiliary system experiments about maintenance management system. All kinds of airborne system maintenance project are considered, and the students themselves should look up relevant civil aviation laws and administrative regulations and advisory circulars and executive order, etc., to understand modern avionics maintenance techniques and master typical maintenance planning method. The design goal is to build a solution for the given tasks independently. Another is query and usage about Airbus aircraft maintenance manual. It can solve the problem of fault isolation task. The students should master the usage of maintenance manuals and the basic maintenance processes. So they can understand the connotation and essence of modern avionics maintenance technology.
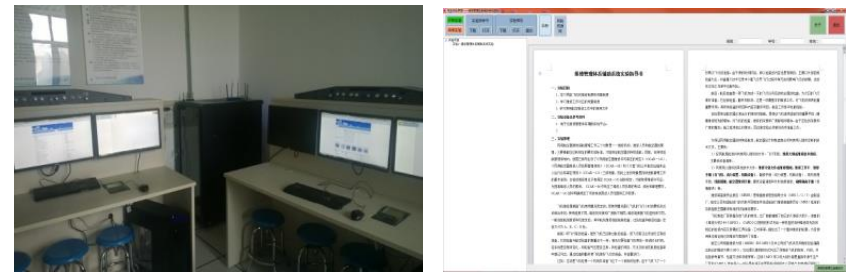

Fig. 1. Assistant platform for electronic maintenance management system
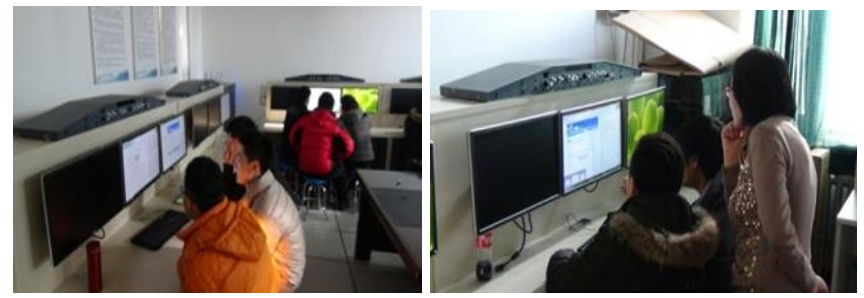

Fig. 2. Students' experimental process and teachers' interpretation process

\section{3) Subject three}

It is for professional teachers to learn avionics license (AV) of typical aircraft model. The training objectives are for young professional teachers to train engineering practice ability accordingly

Training case: Boeing737-700/800AV class II training

Training results: The teacher trained successfully completed the theory studying and the practices on simulation machine and on-job training, and harvest the expected target results.

\section{Teaching Quality Evalution Given by Students to the Young Teachers}

In order to maintain the continuous improvement of professional teachers' comprehensive ability, the growth assessment and continuous improvement suggestion and limited target evaluation system has constructed. The quality of education must be tested out in the end [19].

The following table 1 shows the evaluation to the course of "modern avionics maintenance technology" covered the situation about teaching and studying

TABLE I. EVALUATION RESULTS ABOUT THE COURSE OF “MODERN AVIONICS MAINTENANCE TECHNOLOGY".

\begin{tabular}{|c|c|c|c|c|c|c|c|c|c|c|c|c|c|c|c|}
\hline Evaluation problem & \multicolumn{15}{|c|}{ Part of evaluation results by students } \\
\hline evaluation on preparation adequacy and the amount of information & 95 & 95 & 95 & 95 & 95 & 85 & 95 & 95 & 95 & 85 & 95 & 95 & 95 & 95 & 95 \\
\hline on teaching ideas and difficulties. & 95 & 95 & 95 & 95 & 95 & 95 & 95 & 95 & 95 & 85 & 95 & 85 & 95 & 85 & 95 \\
\hline enough communication and discussion & 95 & 95 & 95 & 95 & 95 & 95 & 95 & 95 & 95 & 95 & 95 & 95 & 95 & 95 & 85 \\
\hline special subject teaching used and heuristic teaching & 95 & 95 & 95 & 95 & 95 & 95 & 95 & 95 & 95 & 85 & 95 & 95 & 85 & 95 & 95 \\
\hline teachers' attitude and enthusiasm & 95 & 95 & 95 & 95 & 95 & 85 & 95 & 95 & 95 & 95 & 95 & 95 & 95 & 95 & 95 \\
\hline students' learning gains and their own learning ability improvement & 85 & 85 & 95 & 95 & 95 & 85 & 95 & 95 & 95 & 85 & 85 & 95 & 85 & 85 & 85 \\
\hline
\end{tabular}


After calculation, the average score was 93.13 and the standard deviation was 3.97. Every evaluation item is over good class. The evaluation results as "excellent" accounted for $87 \%$ to the question 1 . The others are $80 \%$ to question $2,93 \%$ to question $3,87 \%$ to question $4,93 \%$ to question 5 , and $47 \%$ to question $6,53 \%$ to question 7 , and $87 \%$ to question $8,87 \%$ to question 9 and $100 \%$ to question 10 . The results of question 6 and 7 are more consistent with the final paper analysis, which is about understanding the adaptability of the problem. So we had to design a lot of communicating programs in teaching process to enhance students' understanding abilities next teaching year. The experiments show a good result.

\section{CONCLUSIONS}

This paper aims to promote the ability of young teachers for industry-college like Civil Aviation University of China (CAUC). On the basis of a large number of investigation and study, according to the new requirements about young specialty teacher development in CAUC, that is used to carry out electrical teaching for maintenance engineering, an integrated plan is put forward. The plan is considered the following two preconditions. One is the gaps found. The other is to emphasize the integrated effects of top-level design and development effectiveness of teachers' ability. The plan is a closed loop control logic solution. It is made up of theoretical teaching, experimental teaching, engineering practice and limited objective evaluation and improvement. The implementation of the program shows the universal significance to continuously improve the ability of teachers by means of problem-driving and task-pulling.

\section{ACKNOWLEDGMENT}

This paper was supported by the teaching quality and teaching reform research projects of Tianjin for undergraduate course of common colleges and universities.

\section{REFERENCES}

[1] Ministry of Education of the People's Republic of China Ministry of Finance of the People's Republic of China Opinions on the implementation of the "teaching quality and teaching reform project of higher education" during the "Twelfth Five Year Plan" Teach high [2011]6 number (Chinese)

[2] Liu Qian LiYanan Young teachers in Colleges and Universities: where is the road to development [Z] Guangming Daily May 1012 Educational time and space (Chinese)

[3] Li Yan-hui O. A. Mashkina The federal state education standards of the third generation for higher education in Russia: background, structure and features [J] Journal of Higher Education Feb. ,2014 Vol.35 No.2 102-109 (Chinese)

[4] Fan Yi-hong Ke Dan-yun Research in teachers' development in Finland University----Empirical study of Helsinki University [J] Journal of Xinjiang Normal University (Social Sciences) Sep. 2012 Vol.33 No. 5 79-86 (Chinese)

[5] Ye Wei-min The research on the young faculty instructional development of American University----Case study on the University of Michigan [D] Master Degree Dissertation Fujian Normal University June 2013 Supervisor: Professor Xu Ming (Chinese)

[6] Li Li A study on staff development in higher education in UK [D] Doctor Degree Dissertation Southwest University Apr. 2013 Supervisor: Professor Chen Shijian (Chinese)

[7] Zhu Xiaohong A study on continuing teacher professional development of university [D] Doctor Degree Dissertation Tianjin University March 2011 Supervisor: Professor Wang Shuen (Chinese)

[8] Liu Zhentian Theory, current situation and strategies of college teachers' teaching investment [J] China Higher Education Research 2013 No. 3 14-19, 47 (Chinese)

[9] Luo Zhimin An empirical analysis on university faculty's academic ethics [J] Research in Higher Education of Engineering 2011 No.43 6975 (Chinese)

[10] Xu Jihong A study on the structural model of faculty's teaching capacity [D] Doctor Degree Dissertation Noutheast Normal University May 2013 Supervisor: Professor Dong Yuqi (Chinese)

[11] Jiang Qi studies on the strategy of teacher education ability building in Chinese high education institute [D] Master Degree Dissertation Southwest Jiaotong University May 2010 Supervisor: Professor Jiang Jianmei (Chinese)

[12] Zhang Degao Talents cultivation strategy in college and universities based on the stratification and classication [J] Research in Education Development Jan. 2013 77-80 (Chinese)

[13] Hong Lian How to improve classroom teaching quality of University Teachers [J] Research on Higher Education of Nationalities Nov. 2013 Vol.1 No.6 89-92 (Chinese)

[14] Li Yinzhen Discussion on construction of teaching staff in universities under the perspective of connotative development [J] Higher Education Forum Jun. 2013 No.6 78-82 (Chinese)

[15] Shen Dichen $\mathrm{Li}$ Bin and Zhang Xin Existing questions and countermeasures in teaching of young university teachers under the Background of "Quality Project" [J] Journal of Jilin Normal University (Humanities \& Social Edition) Nov. 2012 No.6 108-111 (Chinese)

[16] Zhu Xinyu Tand Rutian The construction of Young Teachers for professional maintenance engineering $[\mathrm{J}]$ Journal of Civil Aviation Flight University of China Mar. 2009 Vol.20 No.2 14-17 (Chinese)

[17] Cao Miaosun Liang Zhixing Role transition of engineering teachers based on CDIO [J] Higher engineering education research 2012 No.1 88-91 (Chinese)

[18] Li Ying Ma Xiaocong Gao Dianrong Research on young teachers education under CDIO circumstance [J] Research in Teaching Jul. 2010 Vol. No.4 38-40 (Chinese)

[19] Zhou Chuansheng Liu Junfeng On quality project back-feeding the training of young faculty [J] Journal of Higher Education May.2011 Vol.32 No.5 62-64 (Chinese) 